\title{
Connective tissue disorders in pregnancy: maternal and fetal perspective
}

\author{
Nehul Jha ${ }^{1 *}$, Hemangi K. Chaudhari ${ }^{2}$
}

\begin{abstract}
${ }^{1}$ Department of Obstetrics and Gynecology, Lokmanya Tilak Municipal Medical College and General Hospital, Mumbai, Maharashtra, India

${ }^{2}$ Department of Obstetrics and Gynecology, Seth G. S. Medical College and KEM Hospital, Mumbai, Maharashtra, India
\end{abstract}

Received: 29 December 2019

Revised: 23 January 2020

Accepted: 29 January 2020

\section{*Correspondence:}

Dr. Nehul Jha,

E-mail: drnehuljha24@gmail.com

Copyright: (c) the author(s), publisher and licensee Medip Academy. This is an open-access article distributed under the terms of the Creative Commons Attribution Non-Commercial License, which permits unrestricted non-commercial use, distribution, and reproduction in any medium, provided the original work is properly cited.

\section{ABSTRACT}

Background: The objective of this study was to study maternal and fetal outcome in connective tissue disorders in pregnancy.

Methods: This was a retrospective type of observational study done in department of obstetrics and gynecology and department of rheumatology at a King Edward Memorial hospital over a period of 1.5 years. 48 women were included in this study after informed consent. All these women presented with collagen disorders to ANC outpatient department or to rheumatology outpatient department or in emergency. All postpartum patients having connective tissue disorders not recruited during ANC were also included in this study after taking their written, informed and valid consent.

Results: Connective tissue disorders are associated with multiple voluntary and involuntary abortions as well as intrauterine fetal deaths. Even in those women having live births, many undergo cesarean sections due to various indications like fetal distress, poor biophysical profile, non-reassuring non stress test etc. Neonates born to mothers with connective tissue disorders are growth restricted and many of them need intensive care admission. Also, these women were found to have multiple associated medical comorbidities in pregnancy.

Conclusions: The data collected and the results arrived upon should help contribute significant literature regarding collagen disorders in pregnancy and help in better fetal and maternal management during pregnancy.

Keywords: Antiphospholipid antibody syndrome, Autoimmune diseases, Connective tissue diseases, Intrauterine fetal death, Rheumatoid arthritis, Scleroderma, Sjogrens syndrome, Systemic lupus erythematosus

\section{INTRODUCTION}

In 13th century physician Rogerius first noticed a connective tissue disorder and used the term 'Lupus' to describe erosive facial lesions in SLE that were reminiscent of the wolf's bite. ${ }^{1}$

Connective tissue disorders can be put into the following number of groups.

\section{Hereditary connective tissue disorders}

Eg., Ehler Danlos syndrome, Marfan's syndrome and Pseudoxanthoma elasticum.

\section{Autoimmune connective tissue disorders}

Eg., systemic lupus erythematosus, antiphospholipid antibody syndrome, scleroderma and polymyositis. This 
group can be characterized by patients with high titre of antinuclear antibodies (ANA) and antibodies to ribonucleoprotein (anti RNP).

\section{Mixed connective tissue disorders and overlap syndromes}

These feature three different diseases and it is not possible to classify them to a particular disease. ${ }^{2}$

In this study we have evaluated the effect of collagen vascular diseases on pregnancy and maternal and perinatal outcome in such cases.

\section{METHODS}

This was retrospective type of observational study conducted at department of obstetrics and gynecology and department of rheumatology at King Edward Memorial hospital form April 2017 to September 2018.

\section{Inclusion criteria}

- All pregnant and women presenting with collagen disorders to ANC OPD or to rheumatology OPD or in emergency, all postpartum patients having connective tissue disorders not recruited during ANC were included in this study.

\section{Exclusion criteria}

- Patients not willing to participate in the study

- Patients lost to follow-up.

Estimated population size of connective tissue disorders in pregnancy is around fifty-two per year. With the use of Raosoft software for sample size calculation, acceptable margin of error of five percent for a confidence interval of ninety five percent recommended sample size was forty-eight. Hence a total of forty-eight cases were studied.

All patients having connective tissue disorders in pregnancy after having fulfilled the inclusion criteria during the study period were enrolled for study purpose after taking their written, informed and valid consent.
Methodology of this Study was initiated only after ethics committee's permission. All pregnant women presenting with collagen disorders to ANC out-patient department or to rheumatology out-patient department or in emergency, all postpartum patients having connective tissue disorders not recruited during ANC were included in this study after taking their written, informed and valid consent. Neonates were followed up till early neonatal period (the interval from birth to 7 days of age) to assess fetal prognosis. Apgar score, birth weight, preterm/full-term, congenital anomalies need of NICU admission, NICU stay, stillbirth/ neonatal death were noted.

\section{RESULTS}

The data collected from this study was described in terms of frequencies and percentages when appropriate. The statistical performances was evaluated by calculating the mean, mode and median. Computer program Microsoft Excel 2017 was used.

\section{Distribution of patients according to diagnoses}

Table 1: Distribution of patients according to diagnosis.

\begin{tabular}{|c|c|c|}
\hline Diagnosis & $\begin{array}{l}\text { Number of } \\
\text { subjects }(n=48)\end{array}$ & $\%$ \\
\hline $\begin{array}{l}\text { Antiphospholipid } \\
\text { antibody syndrome }\end{array}$ & 23 & 47.91 \\
\hline $\begin{array}{l}\text { Systemic lupus } \\
\text { erythematosus }\end{array}$ & 17 & 35.41 \\
\hline Rheumatoid arthritis & 5 & 10.41 \\
\hline Scleroderma with SLE & 2 & 4.16 \\
\hline Sjogren's syndrome & 1 & 2.08 \\
\hline
\end{tabular}

From a total of 48 cases studied at KEM hospital, authors noted that antiphospholipid antibody syndrome was the most prevalent among all connective tissue disorders in pregnancy followed by systemic lupus erythematosus.

Authors note that antiphospholipid antibody syndrome constituted 47.91 percent and systemic lupus erythematosus comprised 35.41 percent of the cases studied (Table 1).

Table 2: Obstetric outcome in connective tissue disorders in pregnancy.

\begin{tabular}{|llllll|}
\hline Obstetric outcome & SLE & $\begin{array}{l}\text { Rheumatoid } \\
\text { arthritis }\end{array}$ & $\begin{array}{l}\text { APLA } \\
\text { syndrome }\end{array}$ & $\begin{array}{l}\text { Scleroderma } \\
\text { with SLE }\end{array}$ & $\begin{array}{l}\text { Sjogren's } \\
\text { syndrome }\end{array}$ \\
\hline Spontaneous abortion & 4 & - & 4 & - & - \\
\hline Voluntary abortion & 1 & - & - & 1 & - \\
\hline FTND & 5 & - & 8 & - & - \\
\hline PTVD & - & 2 & 2 & - & - \\
\hline Preterm LSCS & 3 & 1 & 4 & 1 & 1 \\
\hline Full term LSCS & 4 & 1 & 5 & - & - \\
\hline Emergency exploratory laparotomy & - & 1 & - & - & - \\
\hline
\end{tabular}




\section{Obstetric outcome in connective tissue disorders in pregnancy}

Authors note that out of 48 subjects, $17(35.41 \%)$ underwent vaginal delivery while 20 out of $48(41.66 \%)$ underwent caesarean section for various indications.

A significant proportion (16.66\%) of patients had spontaneous abortion indicating the increased risk of abortion in patients with connective tissue disorders. Out of 17 patients of systemic lupus erythematosus, 4 (23\%) had spontaneous abortion.

Among systemic lupus erythematosus patients, only 5 out of $17(29 \%)$ had normal vaginal delivery while 7 out of 17 i.e. $42 \%$ had caesarean section. $18 \%$ underwent preterm caesarean section. Out of 5 patents of rheumatoid arthritis, 40 percent that is 2 patients had preterm vaginal delivery. 3 underwent caesarean section out of which one underwent exploratory laparotomy in view of uterine rupture. Authors further note that in 23 patients of antiphospholipid antibody syndrome, $17 \%$ had spontaneous abortion. $39 \%$ i.e. 9 out of 23 underwent caesarean section out of which $17 \%$ had preterm lower segment caesarean section and $22 \%$ had full term caesarean section.
There were only two patients of scleroderma with systemic lupus erythematosus. One underwent medical termination of pregnancy and other had preterm lower segment caesarean section. There was only one patient with Sjogren's syndrome who underwent pre term lower segment caesarean section in view of poor biophysical profile followed by exploratory laparotomy in view of rectus muscle hematoma. A significant proportion $(16.66 \%)$ of patients had spontaneous abortion indicating the increased risk of abortion in patients with connective tissue disorder (Table 2).

\section{Maternal medical outcome in patients of connective tissue disorders in pregnancy}

Authors noted that out of 48 patients with connective tissue disorders, 21 had associated medical conditions as shown in the figure above. The most common of them were renal disorders seen in $24 \%$. Out of 5 patients with renal disorders, 4 had systemic lupus erythematosus. Second commonest condition was hypertensive disorders (gestational hypertension, preeclampsia and chronic hypertension) seen in $23 \%$ of these patients. Out of the 5 cases of hypertensive disorders, 3 i.e. $60 \%$ were seen in APLA syndrome.

Table 3: Maternal medical outcome in connective tissue disorders in pregnancy.

\begin{tabular}{|lllll|}
\hline & SLE & Rheumatoid arthritis & APLA syndrome & Scleroderma with SLE \\
\hline Thrombocytopenia & - & - & 1 & - \\
\hline Gestational hypertension/pre-eclampsia & 1 & - & 2 & - \\
\hline Chronic hypertension & 1 & - & 1 & - \\
\hline Pulmonary artery hypertension & - & - & - & - \\
\hline Renal disease & 4 & - & 1 & - \\
\hline Liver disorders & 1 & - & 2 & - \\
\hline Haemolytic anaemia & 2 & - & - & - \\
\hline Retinal vasculitis & 1 & - & - & - \\
\hline Gestational diabetes mellitus & 3 & - & - & - \\
\hline
\end{tabular}

Table 4: Fetal outcome in connective tissue disorders in pregnancy.

\begin{tabular}{|lllllll|} 
& SLE & $\begin{array}{l}\text { Rheumatoid } \\
\text { arthritis }\end{array}$ & $\begin{array}{l}\text { APLA } \\
\text { syndrome }\end{array}$ & $\begin{array}{l}\text { Scleroderma with } \\
\text { SLE }\end{array}$ & $\begin{array}{l}\text { Sjogren's } \\
\text { syndrome }\end{array}$ & $\begin{array}{l}\text { Total } \\
\text { Full term }\end{array}$ \\
\hline Preterm & 5 & 1 & 10 & - & - & 1 \\
\hline IUGR & 2 & 2 & 6 & - & - & 1 \\
\hline IUFD/MSB/FSB & & 2 & 4 & - & - & 6 \\
\hline NICU admission & 4 & 2 & 3 & 1 & 1 & 5 \\
\hline
\end{tabular}

In systemic lupus erythematosus, out of 17 patients, almost 13 were associated with medical comorbidities. One patient had pre-eclampsia, 1 had liver disorder, 1 had chronic hypertension, 4 had renal disorder, 2 had hemolytic anemia, 1 had retinal vasculitis and 3 had associated gestational diabetes mellitus or overt diabetes mellitus.
In antiphospholipid antibody syndrome, out of 23 patients almost 7 had associated medical comorbidities. Gestational hypertension and liver disorder were most common of them with 8.69 percent patients suffering from each. There were only two patients with SLE with scleroderma, and none had any medical comorbidities. 
There was one patient with Sjogren's syndrome and she had pulmonary artery hypertension (Table 3 ).

\section{Fetal outcome in connective tissue disorders}

Authors further note that 33 out of 48 i.e. $68.75 \%$ were live births. Out of live births, $54.54 \%$ were full term while $45.45 \%$ were preterm neonates. Out of 33 live births, 11 i.e. $33.33 \%$ live births needed NICU admission. $10.41 \%$ pregnancies in our study resulted in intrauterine fetal deaths out of which $4.16 \%$ were fresh stillbirths and $6.25 \%$ were macerated stillbirths.

In patients with systemic lupus erythematosus, 12 out of 17 (70.58) had live births. Out of them 7 (58.33\%) were full term babies and $5(41.66 \%)$ were preterm. 2 babies had intrauterine growth retardation and one had low birth weight. $4(33.33 \%)$ babies needed NICU admission. In patients with antiphospholipid antibody syndrome, 23.07 percent had missed abortion. 3 out of 23 i.e. $16 \%$ were intrauterine fetal deaths. 16 out of 23 i.e. $69.5 \%$ were live births out of which 10 were full term while $6(37.5 \%)$ were preterm. Among 5 patients of rheumatoid arthritis, 40 percent were intrauterine fetal deaths, 20 percent were full term and 40 percent were preterm. One of the fullterm babies was low birth weight. Overall 2 infants (40\%) needed NICU admission. There were two patients with scleroderma with systemic lupus erythematosus. One had missed abortion and one gave birth to a preterm infant (Table 4).

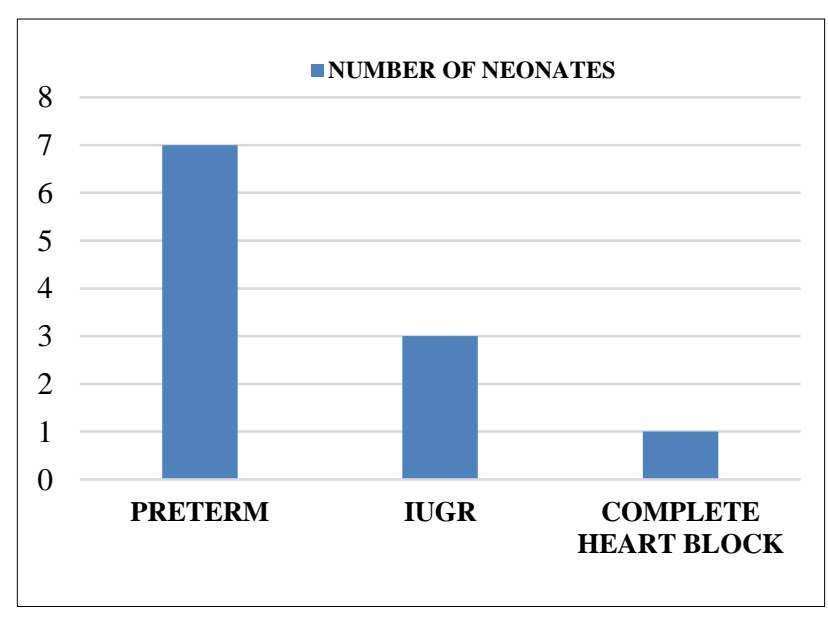

Figure 1: Indications for NICU admission.

\section{Indication for NICU admission}

Out of 33 live births, 11 i.e. $33.33 \%$ live births needed NICU admission.

The most common indication of NICU admission was preterm birth followed by intrauterine growth retardation. Preterm neonate of a woman of Sjogrens syndrome had complete heart block and was admitted in NICU for the same (Figure 1).

\section{DISCUSSION}

Autoimmune disorders in pregnancy pose many difficult situations for the obstetricians during diagnosis and treatment. Pregnancy in patients with autoimmune diseases remains at high risk. Vigilant monitoring of antenatal patients however, averts many maternal and fetal complications. Close fetal surveillance improves outcome.

\section{SLE}

Women with SLE generally experience an increase in disease activity during pregnancy. ${ }^{3-5}$

Out of 17 patients of systemic lupus erythematosus, 4 i.e. $23 \%$ had spontaneous abortion.

MoladvY, Borkowski $\mathrm{T}$ et al, of Tel Aviv university, Israel studied 29 pregnancies with systemic lupus erythematosus prospectively and found that $20.7 \%$ in their study had spontaneous abortions. ${ }^{6}$

Similarly, Carmona F et al, in their study of 60 cases of SLE found $5 \%$ miscarriages and $6.5 \%$ voluntary abortions. $^{7}$

Mankee A et al, in their study "Lupus anticoagulant, disease activity and low complement in the first trimester are predictive of pregnancy loss" found that among those with lupus anticoagulant test positive during first trimester, 6/16 (38\%). experienced a pregnancy loss as compared to only $16 / 186(9 \%)$ of other pregnancies ( $\mathrm{p}=$ 0.003 ). In our study too, out of 4 SLE patients who had spontaneous abortion, 3 were LA positive. ${ }^{8}$

In this study only 5 out of 17 i.e. $29 \%$ had normal vaginal delivery while 7 out of 17 i.e. $42 \%$ had cesarean section.

In this study, out of 17 patients of systemic lupus erythematosus, 13 were associated with medical comorbidities of which most common was renal disorder seen in 4 i.e. $23.5 \%$ of SLE patients followed by pre gestational and gestational diabetes mellitus seen in $17.6 \%$ patients. Hypertensive disorders (11.76\%) and hemolytic anaemia $(11.76 \%)$ were also seen.

Vengetesh PM et al, found similar results in their study in which pre-eclampsia and gestational diabetes mellitus were the most commonly seen maternal complications in SLE.

In this study in patients with systemic lupus erythematosus, out of 17 only 12 had live births. Out of them 7 (58.33) were full term babies and 5 (41.66\%) were preterm. 2 babies had intrauterine growth retardation.

In this study, 7 out of 12 were low birth weight babies and 4 babies needed NICU admission for prematurity. 
In the study by Carmona $\mathrm{F}$ et al, obstetric complications in remaining 53 pregnancies having live births included: preterm delivery, 11 cases $(20.8 \%)$; intrauterine growth retardation, five cases $(9.4 \%)$ and low birth weight in 13 cases. $^{7}$

Similar results were found by Vengetesh PM et al in their study in which out of 8 live births $6(75 \%)$ had preterm delivery, 2 babies had fetal growth restriction and 3 needed NICU admission. ${ }^{9}$

Andrew Smyth in his study "a systematic review and meta-analysis of pregnancy outcomes in patients with systemic lupus erythematosus and lupus nephritis" had found significant associations between lupus nephritis and both premature births and preeclampsia. ${ }^{10}$ In their study, 1842 patients with 2751 pregnancies were studied in which the induced abortion rate was $5.9 \%$, and when excluded, fetal complications included spontaneous abortion (16.0\%), stillbirth (3.6\%), neonatal deaths $(2.5 \%)$, and intrauterine growth retardation $(12.7 \%)$. The unsuccessful pregnancy rate was $23.4 \%$, and the premature birth rate was $39.4 \%$.

Gladman DD et al, in their study 'the effect of lupus nephritis on pregnancy outcome and fetal and maternal complications" found that fetal complications were not different between SLE patients with and without lupus nephritis with the exception of low birth weight and congenital malformations, which were observed more frequently in the renal group. Renal disease was more commonly associated with pregnancy-induced hypertension. ${ }^{11}$

In this study too, 4 of 17 SLE patients had lupus nephritis. Three out of them underwent cesarean section. All four had live births out of which two had preterm neonates.

\section{Rheumatoid arthritis}

Rheumatoid arthritis is the only connective tissue disease for which most reports show clinical improvement during pregnancy. Although most patients note having milder symptoms by the end of the first trimester, they also note some exacerbation of symptoms shortly after delivery.

In our study there were 5 patients of rheumatoid arthritis. In 40 percent i.e. 2 had preterm vaginal delivery. Two underwent preterm cesarean section out of which one underwent exploratory laparotomy in view of uterine rupture. One had full term cesarean section.

Barnabe $\mathrm{C}$ in his study of 38 Canadian women with rheumatoid arthritis, found that a large proportion of women with rheumatoid arthritis $(34.2 \%)$ were delivered by cesarean section. ${ }^{12}$

In this study among 5 patients of rheumatoid arthritis, 40 percent were intrauterine fetal deaths. Out of them one was fresh stillbirth due to uterine rupture and one was macerated stillbirth of 30 weeks (cause not known).

A total 20 percent were full-term and 40 percent were preterm. One of the full-term babies was low birth weight. Overall 2 infants needed NICU admission.

Clowse MEB et al, however in their study of 75 women with rheumatoid arthritis, found that a total of $41 \%$ of the RA pregnancies had an adverse outcome (miscarriage, preterm delivery, or infant abnormality), compared to $20 \%$ of control pregnancies. ${ }^{13}$

Barnabe $\mathrm{C}$ et al, found similar neonatal outcome in rheumatoid arthritis. In his study of 38 women, $21 \%$ had preterm births while $29.8 \%$ babies needed intensive care admission. ${ }^{14}$

Out of 5 women of rheumatoid arthritis in our study 3 had improvement in symptoms of rheumatoid arthritis though disease activity pre and post pregnancy could not be compared due to unavailability of pre pregnancy investigations.

Majority of patients (66-75\%) experience symptoms improvement during pregnancy. This improvement usually begins in first trimester lasts up to few weeks of postpartum period. ${ }^{14,15}$

In spite of the observations in this study, data now shows that for women with well controlled rheumatoid arthritis, pregnancy outcomes are comparable to the general obstetric population, whereas higher levels of RA disease activity are associated with increased risk of less favorable pregnancy outcomes. ${ }^{16}$

Further prednisolone use during pregnancy was linked to lower gestational age at birth. In this study too, 3 out of 5 patients were on prednisolone and 2 had preterm birth while one was intrauterine fetal death.

\section{APLA syndrome}

Literature quotes patients with antiphospholipid syndrome, miscarriage is the most common fetal complications followed by fetal loss and premature birth, whereas the most common maternal manifestations were preeclampsia, followed by eclampsia and abruptio placentae. $^{17}$

In this study there were 23 patients with antiphospholipid antibody syndrome. In 23 patients of antiphospholipid antibody syndrome, $17 \%$ had spontaneous abortion.

A total $39 \%$ i.e. 9 out of 23 underwent cesarean section out of which $17 \%$ had preterm lower segment cesarean section.

Similar results were found by Venkatesh PM et al, in their study "autoimmune disorders in pregnancy: 
maternal and fetal outcome". ${ }^{19}$ Out of 41 patients reaching third trimester, 4 were delivered preterm out of which two had fetal growth restriction with fetal distress and the one was delivered due to imminent eclampsia. Only three patients had vaginal delivery while the rest 16 i.e. $39.02 \%$ were delivered by cesarean section. ${ }^{9}$

Aboubakar M et al, in their study "pregnancy outcome of women with antiphospholipid antibody syndrome" found that out of 34 patients with APLA syndrome cesarean sections were performed on 24 women, representing $71 \% .^{18}$

In this study, in patients with antiphospholipid antibody syndrome, 3 out of 23 i.e. $16 \%$ were intrauterine fetal deaths. 16 out of 23 i.e. $69.5 \%$ were live births out of which 10 were full term while $6(37.5 \%)$ were preterm.

Similarly, Venkatesh PM et al, in their study "autoimmune disorders in pregnancy: maternal and fetal outcome" found that out of total 41 patients with APLA syndrome 19 had live births. Out of 19 there were 4 i.e., $21 \%$ preterm neonates and $21 \%$ neonates with intrauterine growth retardation. ${ }^{9}$

In this study also $4(25 \%)$ out of 16 live births had fetal growth restriction and $4(25 \%)$ neonates had low birth weight. Out of 16 live births, 3 (18.75\%) needed intensive care admission.

Vengetesh PM also found that before diagnosis and treatment, out of 41 only 9 patients reached third trimester and among those nine, preeclampsia and its sequelae were the notable complications observed in five patients. ${ }^{9}$

In this study also out of 23 patients of antiphospholipid antibody syndrome 7 had associated medical comorbidities. Gestational hypertension and liver disorder were most common of them with 8.69 percent patients of each.

Poor pregnancy outcomes, including second trimester loss, fetal growth restriction and preeclampsia were observed in association with APLA for years, but only recently it has been recognized that the lupus anticoagulant is the primary predictor of poor pregnancy outcomes in women. ${ }^{19}$

The outcomes of different treatments - including aspirin, steroids, intravenous globulin and heparin - given to improve pregnancy outcome of women with recurrent miscarriage associated with antiphospholipid antibodies were analyzed in a meta-analysis. This meta-analysis reported that aspirin plus unfractionated heparin is the only treatment combination that leads to a significant increase in the live birth rate among women with antiphospholipid syndrome. Miscarriage rate is reduced by $54 \%$ with this treatment combination (aspirin plus unfractionated heparin compared with aspirin alone). ${ }^{20}$
In this study, out of 23 Antiphospholipid antibody syndrome patients, 8 had received this combination treatment while 15 had not. 6 out of 8 patients $(75 \%)$ receiving this treatment had live births while out of 15 not receiving this treatment, only 10 i.e. $66.66 \%$ had live births.

\section{Sjogren's syndrome}

Sjögren syndrome is known to occur more commonly in women. Affected women are likely to experience more complicated pregnancies than are women without the disease. $^{21,22}$

The effect of autoimmune disease on pregnancy varies according to the maternal disease, disease activity, severity of organ damage, antibody profile, and drug treatment. $^{23}$

An increase in frequency of cesarean delivery was observed in patients with Sjögren syndrome. ${ }^{24}$

In this study there was only one patient with primary Sjogren's syndrome who underwent preterm lower segment cesarean section in view of poor biophysical profile followed by exploratory laparotomy in view of rectus muscle hematoma.

One of the most dreaded complications found in pregnancies in patients with Sjögren syndrome is CHB. In this patient of Sjogrens syndrome too, the neonate born was preterm and had congenital complete heart block and needed intensive care management for the same.

A woman is at risk of delivering a CHB affected baby if she is anti-SS-A positive. ${ }^{25}$ Frequent surveillance is required for at-risk pregnancies by serial echocardiograms and obstetric sonograms between 16 to 20 weeks of gestation and thereafter. The goals are early diagnosis and treatment of incomplete CHB, and improving the outcome for the fetus. ${ }^{26}$

Hussein SZ in their study "pregnancy and fetal outcome in women with primary Sjögren's syndrome" studied 16 cases of pregnancies with Sjogren's syndrome. Seventytwo $(90 \%)$ of the deliveries ended at term in the controls (80) versus $14(87 \%)$ in the cases. Premature birth occurred in $8(10 \%)$ of the controls versus $2(13 \%)$ of the cases. Newborn of women with primary Sjogren's syndrome were characterized by greater birthweight deviation as compared with controls, and $25 \%$ of these babies were small-for-gestational age (SGA) as compared with $7.5 \%$ in controls. ${ }^{24}$

\section{Scleroderma}

In the past, patients having scleroderma were thought to be at high risk for poor fetal and maternal outcome, but some current retrospective studies show that overall maternal and neonatal survival is good despite increased 
risk of small for gestational age fetus. Thus, at present, with close monitoring and appropriate therapy most scleroderma patients can sustain a successful pregnancy. Therapy with hydroxychloroquine and low dose steroids, intravenous immunoglobulins can also be helpful. Renal crisis remains one of the most dreaded complication of a scleroderma pregnancy and necessitates prompt institution of ACE inhibitor therapy despite its potential teratogenicity.

In this study, there were two patients of scleroderma who had coexisting systemic lupus erythematosus. Out of them, one had medical termination of pregnancy in view of risk of child being born with serious physical or mental handicap (patient was on hydroxychloroquine) and one had preterm lower segment cesarean section at 34 weeks in view of non-reassuring non stress test.

Taraborelli $\mathrm{M}$ et al, in their study "Brief Report: Successful pregnancies but a higher risk of preterm births in patients with systemic sclerosis: an Italian multicenter study" prospectively collected data on ninety-nine (99) women with scleroderma from 25 Italian centers and analyzed them retrospectively. Women with scleroderma were observed during 109 pregnancies (from 2000 to 2011), and outcomes were compared with those of the general obstetric population (total of 3,939 deliveries). They found that scleroderma patients had a significantly increased frequency of preterm deliveries $(25 \%$ versus $12 \%$ ) as compared to the general obstetric population. ${ }^{27}$

They also observed increased rate of intrauterine growth restriction (6\% versus $1 \%$ ), and babies with very-low birth weight ( $5 \%$ versus $1 \%$ ). Also, use of corticosteroids was associated with increased rate of preterm deliveries.

\section{CONCLUSION}

The results obtained from this study demonstrate the maternal and fetal outcome in various connective tissue diseases like antiphospholipid antibody syndrome, systemic lupus erythematosus, rheumatoid arthritis, scleroderma and Sjogrens syndrome in pregnancy.

Connective tissue disorders are associated with multiple voluntary and involuntary abortions as well as intrauterine fetal deaths. Even in those women having live births, many undergo caesarean sections due to various indications like fetal distress, poor biophysical profile, non-reassuring non stress test etc.

Neonates born to mothers with connective tissue disorders are growth restricted and many of them need intensive care admission.

The data collected and the results arrived upon should help contribute significant literature regarding collagen disorders in pregnancy and help in better fetal and maternal management during pregnancy.

\section{ACKNOWLEDGMENTS}

Authors would like to express this special thanks to all patients of connective tissue disorders at KEM hospital who consented to participate in this research. Authors would also like to thank this institute Seth G S Medical college for facilitating this research.

Funding: No funding sources

Conflict of interest: None declared

Ethical approval: Not required

\section{REFERENCES}

1. Manole $\mathrm{C}$, Inimioara $\mathrm{MC}$, Isabela $\mathrm{S}$, Camelia DV. Manifestations of systemic lupus erythematosus. Maedica (Buchar). 2011;6(4):330-6.

2. Carcassi U, Passiu G. Collagenopathic cardiopathies. II Cattedra di Reumatologia; 1991;6(4 Pt 2):483-90.

3. Clowse ME. Lupus activity in pregnancy. Rheum Dis Clin North Am. 2007;33(2):237-52.

4. Petri M, Howard D, Repke J. Frequency of lupus flare in pregnancy. The Hopkins lupus pregnancy center experience. Arth Rheumat. 1991;34(12):153845.

5. Urowitz MB, Gladman DD, Farewell VT, Stewart J, McDonald J. Lupus and pregnancy studies. Arth Rheumat. 1993;36(10):1392-7.

6. Molad Y, Borkowski T, Monselise A, Ben-Haroush A, Sulkes J, Hod M, et al. Maternal and fetal outcome of lupus pregnancy: a prospective study of 29 pregnancies. Lupus. 2005;14(2):145-51.

7. Carmona F, Font J, Cervera R, Muñoz F, Cararach $\mathrm{V}$, Balasch J, et al. Obstetrical outcome of pregnancy in patient with systemic Lupus erythematosus. A study of 60 cases. Eur J Obstet Gynecol Reprod Biol. 1999;83(2):137-42.

8. Mankee A, Petri M, Magder LS. Lupus anticoagulant, disease activity and low complement in the first trimester are predictive of pregnancy loss. Lupus Sci Med. 2015;2:e00095.

9. Vengetesh PM, Hebbar S, Rai L. Autoimmune diseases in pregnancy: maternal and fetal outcomes. Int J Reprod Contracept Obstet Gynecol. 2015;4(1):9-14.

10. Smyth A, Oliveira GH, Lahr BD, Bailey KR, Norby SM, Garovic VD. A systematic review and metaanalysis of pregnancy outcomes in patients with Systemic Lupus Erythematosus and Lupus Nephritis. Clin J Am Soc Nephrol. 2010;5(11):2060-8.

11. Gladman DD, Tandon A, Ebanez D. The effect of lupus nephritis on pregnancy outcome and maternal and fetal complications. J Rheumatol. 2010;37(4):754-8.

12. Barnabe C, Faris PD, Quan H. Canadian Pregnancy Outcomes in Rheumatoid Arthritis and Systemic Lupus Erythematosus. Int J Rheumatol. 2011:2011.

13. Clowse MEB, McDaniel G, Eudy AM. Pregnancy in Rheumatoid Arthritis: a retrospective study. Clin Rheumatol. 2018;37(3):789-94. 
14. Persellin RH. The effect of pregnancy on rheumatoid arthritis. Bull Rheum Dis. 1976-1977;27(9):922-7.

15. Ostensen $M$. The influence of pregnancy on blood parameters in patients with rheumatic disease. Scand J Rheumatol. 1984;13(3):203-8.

16. Bharti B, Lee SJ, Lindsay SP, Wingard DL, Jones $\mathrm{KL}$, Lemus $\mathrm{H}$, et al. Disease severity and pregnancy outcomes in women with rheumatoid arthritis: Results from the organization of teratology information specialists' autoimmune diseases in pregnancy project. J Rheumatol. 2015;42:1376-82.

17. Cervera R, Khamashta MA, Shoenfeld Y, Camps MT, Jacobsen S, Kiss E, et al. Morbidity and mortality in the antiphospholipid syndrome during a 5-year period: a multicentre prospective study of 1000 patients. Ann Rheum Dis. 2009;68(9):1428-32.

18. Aboubakar M, Klikpezo R, Tognifode M, Denakpo JL, Zouari F. Pregnancy outcome of women with antiphospholipid syndrome, a retrospective descriptive case study. Gynecol Obstet (Sunnyvale). 2017;7(435):2161-0932.

19. Davis SM, Branch DW. Thromboprophylaxis in pregnancy: Who and How? Obstet Gynecol Clin North Am. 2010:37(2):333-43.

20. Empson M, Lassere M, Craig J, Scott J. Prevention of recurrent miscarriage for women with antiphospholipid antibody or lupus anticoagulant. Cochrane Database Syst Rev. 2005;(2):CD002859.

21. Sisamopoulou-Mavridou A, Manoussakis $\mathrm{MN}$, Mavridis AK, Moutsopoulos HM. Outcome of pregnancy in patients with autoimmune rheumatic disease before the disease onset. Ann Rheum Dis. 1988;47(12):982-7.

22. Skopouli FN, Papanikolaou S, Malamou-Mitsi V, Papanikolaou N, Moutsopoulos HM. Obstetric and gynecological profile in patients with primary Sjögren's syndrome. Ann Rheum Dis. 1994;53(9):569-73.

23. Carvalheiras G, Faria R, Braga J, Vasconcelos C. Fetal outcome in autoimmune diseases. Autoimmun Rev. 2012;11(6-7):A520-30.

24. Hussein SZ, Jacobsson LT, Lindquist PG, Theander E. Pregnancy and fetal outcome in women with primary Sjogren's syndrome compared with women in the general population: a nested case-control study. Rheumatol (Oxford). 2011;50(9):1612-7.

25. Brucato A, Cimaz R, Caporali R, Ramoni V, Buyon J. Pregnancy outcomes in patients with autoimmune diseases and anti-Ro/SSA antibodies. Clin Rev Allergy Immunol. 2011;40(1):27-41.

26. Rosenthal D, Druzin M, Chin C, Dubin A. A new therapeutic approach to the fetus with congenital complete heart block: preemptive, targeted therapy with dexamethasone. Obstet Gynecol. 1998;92(4 Pt 2):689-91.

27. Taraborelli M, Brucato A, Airò P, Bajocchi G, Bellisai F, Biasi D, et al. Successful pregnancies but a higher risk of preterm births in patients with systemic sclerosis: an Italian multicenter study. Arth Rheumat. 2012;64(6):1970-7.

Cite this article as: Jha N, Chaudhari HK.

Connective tissue disorders in pregnancy: maternal and fetal perspective. Int J Reprod Contracept Obstet Gynecol 2020;9:1124-31. 